\title{
Free Arterial Graft
}

National Cancer Institute

\section{Source}

National Cancer Institute. Free Arterial Graft. NCI Thesaurus. Code C117816.

A vessel graft comprised of an artery that has been completely detached from its orig inal location. 